\title{
Personalização, consumo e transtornos ambientais
}

\author{
Customization, consumption and environmental disturbances
}

\author{
Augusto Antônio Fontanive Leal \\ Doutorando em Direito na Pontifícia Universidade Católica do Rio Grande do Sul \\ (PUCRS) \\ augustoafleal@gmail.com
}

\begin{abstract}
Resumo: O presente artigo busca realizar uma análise sobre as relações de consumo no cenário de uma sociedade individualizada pós-moderna e seus impactos no ambiente. A pesquisa será realizada por meio: (a) da contextualização da característica social que possibilita aos indivíduos a busca por sua autonomia pela personalização; (b) do estudo do consumo em uma sociedade pós-moderna dotada de flexibilidade no âmbito das relações entre indivíduo e Estado; (c) da constatação dos impactos na crise ambiental a partir das relações de consumo anteriormente estudadas. Com isso, revela-se como objetivo deste artigo analisar a correlação entre a busca do indivíduo por personalização na indução para o consumo e a crise ambiental. A conclusão aponta para o fato de que as desregradas relações de consumo acabam dispondo da natureza como um mero estoque de recursos naturais, desconsiderando-a como um todo. A pesquisa será qualitativa amparada pelo método hermenêutico com uso de pesquisa bibliográfica e documental.
\end{abstract}

Palavras-chave: Personalização. Relações de consume. Ambiente. Crise ambiental.

Abstract: In this paper I seek to carry out an analysis on the relations of consumption in the scenario of a postmodern individualized society and its impacts on the environment. The research is carried out through: (a) the contextualization of the social characteristic that enables individuals to search for their autonomy through personalization; (b) the study of consumption in a postmodern society endowed with flexibility in the relations between individual and State; (c) the verification of the impacts on the environmental crisis from the consumer relations previously studied. With this, it is revealed as the objective of this article to analyze the correlation between the individual's search for personalization in the induction to consumption and the crisis of the environment. My conclusion points to the fact that the unruly consumer relations end up disposing of nature as a mere stock of natural resources, disregarding it as a whole. It's a qualitative research supported by the hermeneutic method with the use of bibliographical and documentary research.

Keywords: Personalization. Consumer relations. Environment. Environmental crisis. 


\section{Introdução}

As sociedades pautadas em um elevado grau de desenvolvimento passam por uma nova caracterização em seus aspectos literários, artísticos e científicos. Surge a ideia de uma nova sociedade que descontinuando a linha histórica, arranca a enraizada modernidade do contexto social e abre as portas para a entrada do seu estágio posterior: a pós-modernidade.

É com base na reforma trazida pela pós-modernidade, em um ambiente globalizado no qual o tempo e o espaço sofrem uma ruptura de sua outrora necessária ligação, que se tem a nova sociedade pautada no fluxo contínuo de informações e nas relações sociais que ocorrem em tempo e espaço distintos. Nessas condições, em uma flexibilizada relação entre Estado e indivíduo, surge a busca destes pela autonomia e personalização, mormente nas relações de consumo pós-modernas. Aliando essas perspectivas à crise ambiental, é possível desvendar qual a relação entre a busca por personalização e a degradação da natureza.

Por certo que as relações entre indivíduo e Estado foram reformadas, o que já se demonstrou consolidado com base na diminuição da vertente de um Estado-providência. Igualmente, as relações de consumo possuem, por meio de estratégias de marketing e campanhas publicitárias, um caráter sedutor que leva os indivíduos a consumirem cada vez mais. Para tanto, busca-se estabelecer uma ligação entre essas constatações com os impactos que são demonstrados na crise ambiental, concebendo a importância de se analisar as causas de um iminente colapso, ainda que a personalização por meio do consumo não seja a sua única causa.

A pesquisa, assentada no campo da sociologia jurídica ambiental, será qualitativa, realizada pelo método hermenêutico e com uso de pesquisa bibliográfica e documental, será estruturada em três capítulos. No primeiro capítulo, é descrito um processo no qual o indivíduo é abduzido pela subjetividade imposta (e auto imposta) que possibilita firmar a sua individualidade social, mormente no curso das estratégias de marketing e campanhas publicitárias de mercadorias. No segundo capítulo, será estudado o fato de que a individualização por intermédio do consumo cria uma nova concepção social pósmoderna, saindo da ótica principal a produção de mercadorias, em decorrência da minimização de problemas tecnológicos, e entrando em cena a sociedade de consumo, onde há um processo de mercantilização inclusive do indivíduo que busca pela sua personalização. Por fim, no terceiro capítulo, encontra-se o busílis gerado por esta 


\title{
LEAL, A. A. F.
}

dependência entre individualização e relações de consumo: a crise ambiental. Assim, será realizada análise no sentido de comprovar que as relações de consumo, cada vez mais possíveis e exageradas, geram o abalo ao ambiente de forma irreversível, ocasionando a escassez dos recursos naturais e a constante degradação ambiental.

\section{A personalização do indivíduo a partir do consumo}

O contexto democrático evidencia certas diretrizes nos processos sociais a ele envolvidos. A busca que se tem por parte do individuo, enquanto membro de uma sociedade, pela sua própria individualidade acaba destacando ainda mais a problemática vivenciada. Não obstante, esta busca por individualização está fundamentada na liberdade que a democracia preza, a qual foi destacada como princípio fundamental do governo democrático por Aristóteles:

\begin{abstract}
O princípio fundamental do governo democrático é a liberdade; a liberdade, diz-se, é o objeto de toda a democracia. Ora, um dos característicos essenciais da liberdade é que os cidadãos obedeçam e mandem alternativamente; porque o direito ou a justiça, em um Estado popular, consiste em observar a igualdade em relação ao número, e não ao que se regula pelo mérito. (2011, p. 248)
\end{abstract}

Porém, a individualização do sujeito, advinda de sua liberdade democrática, não destoa do próprio ambiente gerado pela democracia, como advertira Gilles Lipovetsky (2005, p. 106). Na medida em que na democracia existe a possibilidade de personalização dos indivíduos, há uma valorização da liberdade.

Neste aspecto é que reside outra característica da democracia denunciada por Aristóteles: trata-se do viver como desejado (ARISTÓTELES, 2011, p. 249). Por certo que a ambientação da sociedade em um plano democrática possibilita a individualização diante da personificação dos membros desta sociedade em decorrência da liberdade existente, sendo que esta liberdade encontra respaldo em sua pluralização, isto é, em uma igualização da possibilidade de ser livre e de poder desejar individualmente.

O processo de personalização clama na atualidade por uma incessante demanda pela liberdade, possibilitando aos indivíduos a escolha e a pluralidade. Toda essa busca individualista pelas próprias escolhas advém deste cenário. Passa-se, com isso, por uma crise na democracia, ante a dificuldade de conciliação de diversas personalizações, onde o maior interesse é a liberdade e a diversificação, momento no qual, conforme Gilles Lipovetsky.

O processo de personalização não cessa de reforçar a demanda de liberdade, de escolha e de pluralidade e de agenciar um indivíduo descontraído, fair-play, 
aberto às diferenças. À medida que o narcisismo cresce, a legitimidade democrática predomina, mesmo que de maneira $\operatorname{cool}(\ldots) .(2005$, p. 105)

Essa conjuntura político social desponta em um ambiente de incerteza de anseios de cada indivíduo, a serem moldados em exclusivo por cada membro do corpo social. Com isso, demonstra-se que, apesar de haver um interesse que liga o sujeito ao contexto social, há também algo que o define e o torna exclusivo nas suas perspectivas próprias diante da liberdade concedida pela modernidade, sendo que esta liberdade não pode ser forte o suficiente para arruinar o previamente ajustado para a vida em sociedade.

A importância que se dá para a vida em sociedade é fundamental para assegurar a democracia política, que além de priorizar a liberdade, deve oportunizar a igualdade entre estes indivíduos, tanto igualdade em liberdade, como em oportunidades. É justamente neste ambiente que se tem o conflito entre sociedade e indivíduo, momento no qual é importante trazer à baila o entendimento de Norbert Elias, no âmbito de seus estudos sobre a falta de clareza existente na sociedade hodierna entre a relação da pluralidade de pessoas com o indivíduo e a relação deste com a pluralidade. Entende o autor ser necessário superar o pensamento de que indivíduo e sociedade são duas entidades ontologicamente diferentes, onde se ultrapassa

A mera crítica negativa à utilização de ambos como opostos e se estabelece um
novo modelo da maneira como, para o bem ou para o mal, os seres humanos
individuais ligam-se uns aos outros numa pluralidade, isto é, numa sociedade.
(ELIAS, 1994, p. 7-8)

Para tanto, ainda que o indivíduo corra em prol de sua autonomia e independência, ele estará ligado a outros indivíduos em uma pluralidade, a qual significa a própria sociedade, a partir de sua formação com fundamento no interesse em se viver em sociedade. O ambiente social fornece ao indivíduo a possibilidade de adquirir sua liberdade, mediante uma garantia de segurança que vincula a prática individual à sociedade. Porém, esta segurança passa a ficar comprometida pela atividade individualista que desconsidera a vida inserida em uma ordem social.

Por isso, como predissera Zygmunt Bauman, a liberdade necessita estar vinculada com a sociedade, uma vez que não pode ser garantida quando exercida contra a ordem social (BAUMAN, 2001, p. 28). Isto se dá pelo fato de que a vida regulada em sociedade não permite com generalidade a ausência de situações em que as decisões tomadas não são somente de responsabilidade própria, devendo existir uma previsão de suas consequências, evitando-se um Estado onde reina a incerteza sobre as intenções e movimentos dos sujeitos. A vida em sociedade permite um conhecimento prévio da 


\section{LEAL, A. A. F.}

ordem contida no movimento fluído pós-moderno das relações sociais, de modo a não permitir a ausência de regulação.

Esta conceituação traz à tona a proposta de Anthony Giddens, no sentido de se estar vivendo um ambiente de reflexividade de tal forma que a vida social consiste em práticas sociais constantemente examinadas e reformadas diante da informação renovada sobre estas práticas, o que alteraria seu caráter (GIDDENS, 1991, p. 45), sendo que este estado reflexivo despontaria a condição radical da modernidade atualmente vivenciada (GIDDENS, 1991, p. 57).

É devido a este ambiente, ainda conforme o sociólogo inglês, de separação entre tempo e espaço, com sistemas sociais desencaixados (em decorrência da ruptura entre tempo e espaço) e da reflexividade das relações sociais (GIDDENS, 1991, p. 25), que se concebe esta característica social hodierna, onde a confiança surge como sustentação para que, com base nesta crença na credibilidade de uma pessoa (indivíduo) ou sistema social (GIDDENS, 1991, p. 41), possa-se sustentar a associação social descrita em um ambiente dinâmico e fluído, conforme um conhecimento prévio de ordenação anteriormente referido.

É importante esclarecer que não se compactua com a ideia de se estar vivenciando ainda um período moderno, como entende Anthony Giddens. Concebe-se o despontar de uma pós-modernidade, caracterizada pelos seus fluídos que não fixam mais espaço nem prendem o tempo, como entendera Zygmunt Bauman em sua obra Modernidade Líquida (BAUMAN, 2001, p. 8). A Modernidade Líquida aqui é entendida como sendo a própria concepção de um novo estágio social, em uma circunstância pós-moderna, com a conclusão de que os caráteres determinantes do que seria a modernidade reflexiva disposta por Anthony Giddens devem ser inseridos no contexto da pós-modernidade.

Não é à toa que Norbert Elias referira ser característico das sociedades mais desenvolvidas que as diferenças entre as pessoas se acentuariam por meio de uma alta valorização de suas identidades-eu em contraponto à identidade-nós da sociedade (ELIAS, 1994, p. 130). Por via de consequência, segundo Elias, o que se percebe na pósmodernidade pode ser identificado como um processo de transformação social individualizante que passa o controle do indivíduo, dando azo a possíveis isolamentos e encapsulações dos indivíduos no âmbito de suas relações sociais: 
Tanto a possibilidade quanto a necessidade de maior individualização constituem um aspecto de uma transformação social que ultrapassa em muito o controle do indivíduo. $\mathrm{O}$ produto dessa individualidade crescente, a maior diversidade das pessoas com respeito ao comportamento, à experiência e à composição, não é simplesmente dado pela natureza, no mesmo sentido da diversidade dos organismos humanos. (...). Considerados como corpos, os indivíduos inseridos por toda a vida em comunidades de parentesco estreitamente unidas foram e são tão separados entre si quanto os membros das sociedades nacionais complexas. O que emerge muito mais nestas últimas são o isolamento e a encapsulação dos indivíduos em suas relações uns com os outros. (ELIAS, 1994, p. 103)

Muito embora se objetive uma igualdade na democracia vigente e na complexidade da sociedade, em sua fluidez que destrói a junção entre tempo e espaço, a individualização é um processo aberto na busca pela autonomia dos indivíduos. Disso decorre a transformação dos indivíduos em suas condições dentre as mais variadas, incluindo físicas, intelectuais, econômicas, voltadas cada vez mais para a liberdade em detrimento da igualdade. Em razão disso, afirma Gilles Lipovetsky que,

\begin{abstract}
A igualdade sai da fase moderna e uniforme, recicla-se à era pós-moderna da modulação das alocações sobre os rendimentos reais, da diversificação e personalização dos modos de redistribuição, da coexistência dos sistemas de seguro individual e dos sistemas de proteção social no momento em que, precisamente, a demanda de liberdade é superior à da igualdade. (LIPOVETSKY, 2005, p. 109)
\end{abstract}

Impende que neste caso seja referido que esta igualdade não diz respeito à igualdade fundamental da democracia, no âmbito de todos poderem participar politicamente. Tratase, todavia, da igualdade de personalidade dos indivíduos, o que perpassa uma personificação coletiva em um ambiente pós-moderno em que cada processo de individualização compõe uma demanda pela autonomia e liberdade, mesmo que o interesse democrático seja igualitário para a associação social.

Neste sentido é que a sociedade surge como importante meio para garantir a segurança dos indivíduos, não podendo ser abdicada neste processo de individualização, razão pela qual a crise democrática vivenciada não diz respeito à resistência contra a própria sociedade, visto ser ela a garantidora efetiva do processo individualizatório, uma vez que, como entende Norberto Bobbio, a sociedade é um produto do indivíduo, devendo vir a beneficiar este (BOBBIO, 2000, p. 423). Sendo neste caso que surge a importância da manutenção da sociedade, que possibilita a segurança dos sujeitos no processo de sua individualização. Não destoa deste entendimento a conclusão expressada por Reinaldo Dias, no âmbito da personalização da sociedade em um Estado: 


\section{LEAL, A. A. F.}

Para poder determinar se o Estado tem um fim ou fins, é necessário estabelecer o que se entende por isso, e distingui-los dos fins da atividade política. $\mathrm{O}$ Estado não dispõe de consciência e vontade própria, pois ele somente existe na consciência e na vontade de seus integrantes, e nas suas interações recíprocas e que conforma a instituição estatal. (DIAS, 2008, p. 89)

Por isso, a sociedade passando para a imagem de um Estado, possui um fim necessário. Este Estado, justamente por não possuir consciência própria, subsiste na consciência e vontade dos seus integrantes, que nada mais são do que os indivíduos a quem a sociedade personalizada em Estado deve servir, no âmbito de suas atribuições da democracia da complexa e fluída pós-modernidade.

A busca pela personalização dos indivíduos em um âmbito social, por sua vez, demanda por liberdade autonômica e independente, sendo que esta proposta funda raízes em um preconizado ideal de liberdade proveniente da modernidade, em uma promessa de liberdade de agir e de se portar baseado no pensar racional. Referida liberdade somente poderia ser alcançada dentro de uma coletividade, que ampararia o indivíduo em um estágio de superação do seu status pré-humano (BAUMAN, 2000, p. 77-78).

Porém, a reconsideração das liberdades dos indivíduos que buscam constantemente sua personalização passa a ocorrer em um ambiente no qual a liberdade aspirada não é tão-somente a de agir livremente no critério da racionalidade, estando também no agir para além da igualdade em uma busca cada vez maior de independência das garras do Estado, tratando-se de uma "liberdade face às restrições impostas pela limitação coercitiva das opções individuais" (BAUMAN, 2000, p. 78).

Muito embora, como concebe Martin Carnoy, a ânsia pela liberdade negativa pode estar atrelada à concentração do poder econômico e às novas concepções políticas de modo a acabar sendo gerada uma reconsideração democrática em uma sociedade capitalista (CARNOY, 1988, p. 60-61), por certo que, como elucidara Bauman,

Sem a crença num destino e propósito coletivos do todo social, são os indivíduos que devem, cada um por si, dar sentido à vida. Tarefa que já não era fácil nos melhores tempos, torna-se verdadeiramente desanimadora quando nenhum sentido pode contar com apoio seguro - pelo menos não o bastante para sobreviver ao esforço da própria adoção. (BAUMAN, 2000, p. 76)

Com isso, a perspectiva que se tem no âmbito da individualização não pode se operar com um descrédito completo da democracia política, uma vez que a sociedade necessariamente enseja um interesse comum entre os seus membros, sendo que esta busca por individualização não pode vir a descaracterizar por completo a própria associação social. É neste cenário que se opera o processo de individualização, com uma busca pela 
descaracterização da rigidez das instituições, com nova tomada de rumos para além de um paternalismo estático do Estado sobre a sociedade. Abrem-se as portas para a atuação livre e desimpedida dos indivíduos na busca pela sua personalização, demandando por uma nova perspectiva social e política em seu revelar autonômico.

Nesse espaço que reside a proposta de virada paradigmática de Boaventura de Sousa Santos, ao entender que o Estado deve passar de uma perspectiva impositiva de sociabilidade, promovendo esta reordenação de um paradigma criado para proporcionar as condições para a experimentação, de modo a não apenas transformar o Estado, mas reinventá-lo (SANTOS, 2011, p. 334-335).

Com base no exposto, o processo de individualização deve ser considerado em sua idealização de transformação da identidade humana, consolidando a autonomia de jure (BAUMAN, 2001, p. 40) dos indivíduos membros de uma sociedade dentro de um ambiente democrático que permite a busca de cada indivíduo pela sua personalização.

O processo individualizatório dos membros de uma sociedade caracteriza um cenário de busca por autonomia constante da possibilidade e antevisão de liberdade, em uma igualdade política e democrática, mas não em uma igualdade de personalização, justamente porque cada processo de personalização está amparado pela perspectiva própria de cada um dos indivíduos que trilham por esta via. É neste ambiente que se desvela o papel do consumismo e as relações de consumo na esfera social, as quais estão intimamente ligadas ao processo de individualização, conforme se verá na próxima parte deste trabalho.

\section{As relações de consumo em um ambiente livre para a individualização}

No contexto vivenciado, advindo de uma transição da modernidade para a sua consequência pós-moderna, passa-se por um processo no qual a democracia enfrenta uma crise, a partir da redução da rigidez individual e institucional que reconsidera a verticalização entre Estado e sociedade de forma a propiciar novas políticas sociais, o que coloca em evidência a abertura que se teve para o consumismo em massa (LIPOVETSKY, 2005, p. 109-110).

Deve-se, contudo, compreender que a pretensão da sociedade no consumo a partir da padronização de uma massificação da produção prêt-à-porter passou deste critério para um ideal pós-moderno, que possibilite o processo de personalização do indivíduo, liquefazendo a outrora identidade estática dos sujeitos, ponto em que é necessário dar voz às palavras de Gilles Lipovetsky: 
Na hora dos sistemas à escolha, a personalidade não pode mais ser do tipo gregário ou mimético, mas sim, deve aprofundar sua diferença, sua singularidade: o narcisismo representa esse desprendimento do domínio do Outro, a ruptura com a ordem da padronização dos primeiros tempos da "sociedade de consumo". Liquefação da identidade rígida do Eu (...). (LIPOVETSKY, 2005, p. 39)

É nesta perspectiva narcisista de fuga de uma padronização com a finalidade de alcançar um status individualizado em uma ambiente de fluidez constante que se percebem as relações de consumo contemporâneas. Sem dúvidas, está-se diante de uma mesa de bufê com tantos pratos deliciosos que seria impossível provar todos, como ilustrara Zygmunt Bauman (2001, p. 75). Diante desta mesa de bufê estão os consumidores que possuem a irritante "necessidade de estabelecer prioridades: a necessidade de dispensar algumas opções inexploradas e abandoná-las. A infelicidade dos consumidores deriva do excesso e não da falta de escolha” (BAUMAN, 2001, p. 75). Este cenário delineado pelo citado sociólogo polonês especifica a composição das relações sociais voltadas para o consumo em um cenário pós-moderno, onde o consumidor sofre pelo excesso de possibilidades que lhe aparecem como formas de compor a sua personalização, de acordo com a busca pela própria individualização.

A necessidade que o indivíduo tem de moldar sua personalidade demonstra uma perspectiva insaciável em um campo subjetivo criado pelo constante fluxo de informações publicitárias que como uma enxurrada desvariam o consumidor que pleiteia pela sua personalização. Há um conjunto estratégico de marketing que milita pela venda de um modo de ser, em um inesgotável manejar da liberdade do indivíduo que deseja ser alguém, conforme se verifica em sua possibilidade de ser livre, sendo que esta liberdade está mais condicionada do que o próprio indivíduo pode perceber. A viabilidade de ser livre de um membro de uma sociedade democrática encontra respaldo na proposta estratégica de publicidade, confundindo-se o ser livre com o desejo de ser seduzido por parte do consumidor quando busca se identificar com autonomia e originalidade.

O indivíduo, em sua jornada pela individualização, é levado a consumir como meio para atingir um fim: ser alguém livre e autônomo. Como perscrutam Fred Tavares e Marta de Azevedo Irving, a estratégia de vendas baseada no marketing e na publicidade

Focalizam as pessoas (consumidores) e a venda dos modos de ser. A mercadoria (objeto) é menos importante no discurso do consumo e, no seu lugar, figuram as marcas com espírito, personalidade e valor. Igualmente, se evidencia a insaciabilidade do desejo junto a um consumidor livre, que deseja ser seduzido. (TAVARES; IRVING, 2009, p. 29) 
Neste talante, evidencia-se uma sociedade baseada em relações de consumo por mero consumo, ocasionando a era do consumismo em massa, na qual os produtos não são adquiridos pela sua importância, sendo as marcas e seus simbolismos o verdadeiro desejo do indivíduo que busca se destacar socialmente. As relações de consumo, sob estes critérios, operam em um território de insaciabilidade do consumidor que, além de consumir irrestritamente, almeja ser induzido a comprar.

O consumismo de que se dotam as relações sociais na contemporaneidade pósmoderna, intencionadas pelos indivíduos em sua busca por individualização, chega a ser considerado como uma cultura insaciável de destruição, como atesta Juarez Freitas em seu tratado sobre a sustentabilidade (FREITAS, 2011, p. 27). Por certo que na busca pela personalização em uma sociedade baseada no consumo há um envolvimento subjetivo dos indivíduos por meio de publicidades que tornam a vida dos membros de uma sociedade direcionada para o consumo. Neste ponto, é importante trazer à baila o entendimento de Agostinho Oli Koppe Pereira, Henrique Mioranza Koppe Pereira e Mariana Mioranza Koppe Pereira ao referirem que

\begin{abstract}
A base de toda nossa sociedade se tornou o consumo. A população passou a ser envolvida por publicidades - inicialmente escritas, depois pela televisão e, agora, num misto de tudo, pela internet. Esse contorno publicitário que se manifestou e se manifesta de diversos meios, implícitos e explícitos, torna a vida do cidadão manipulada para o consumo. Tudo isso, sem que o indivíduo perceba e, assim, colabore para que o sistema pré-organizado decorra conforme um jogo já jogado.(PEREIRA; PEREIRA; PEREIRA, 2009, p. 13)
\end{abstract}

Em decorrência disso, a subjetividade do indivíduo acaba sendo moldada pela divulgação publicitária de atendimentos de estratégias de marketing em um ambiente onde os membros da sociedade se voltam para a sua própria individualização. Consequentemente, ainda conforme os mencionados autores, o valor do ser humano acaba por ser condicionado ao consumo (PEREIRA; PEREIRA; PEREIRA, 2009, p. 16), justamente porque ao consumir o indivíduo busca se originalizar e calcificar sua autonomia decorrente da liberdade que lhe é proporcionada na sociedade pós-moderna.

A cultura que faz com que o indivíduo se utilize do consumismo desregrado com a finalidade de se firmar como autônomo e personalizado originalmente encontra respaldo na construção de símbolos representada pela atividade midiática da publicidade constante das estratégias de marketing. Há uma inconteste formação de subjetividades que, no âmbito de uma instabilidade de desejos e insaciabilidade das necessidades baseados no consumo instantâneo adaptado à liquidez do ambiente (BAUMAN, 2008, p. 45) (pós- 


\title{
LEAL, A. A. F.
}

moderno), atua flutuante em um local de liberdade de escolha do indivíduo. Caso que, conforme concluíram Fred Tavares e Marta de Azevedo Irving:

\begin{abstract}
As marcas comerciais constroem símbolos, que se destroem em gozos polissignificantes, através de processos comunicacionais e midiáticos; produzem e fabricam subjetividades, que são identidades revogáveis e flutuantes, à busca de um consumo intenso, interminável, e de um desejo produzido incessantemente (em função de um estado contínuo de excitação e permanente insatisfação). Uma subjetividade que escolhe as marcas tanto por aspectos individualistas, quanto coletivistas, ao mesmo tempo em que se busca através da liberdade individual fazer essas escolhas. (TAVARES; IRVING, 2009, p. 70)
\end{abstract}

Por isso, para a cultura do consumismo as marcas desempenham papel fundamental, pois em sua criação de símbolos desenvolvem uma subjetividade nos indivíduos que vivem em um ambiente político e social no qual a liberdade facilita as relações de consumo. Na criação de símbolos formados pelas marcas são proporcionados ao indivíduo a venda de um ser personalizado, original e autônomo, o que, de acordo com Agostinho Oli Koppe Pereira e Cleide Calgaro, evidencia um ambiente competitivo inconsciente de autoafirmação, calcado no desejo de estar a frente de outro (PEREIRA; CALGARO, 2015, p. 21).

Em razão disso, Zygmunt Bauman entende como errônea a premissa de que o mundo da sociedade de consumidores é dividido entre aquilo que será escolhido e quem escolhe, ou seja, mercadorias e consumidores. Para o autor, opera-se no caso da sociedade de consumidores uma obnubilação que culmina na eliminação da divisão referida, em um ambiente onde somente se torna um sujeito, isto é, se individualiza, aquele que virar antes uma mercadoria (BAUMAN, 2008, p. 20). Este giro compreensivo desponta no entendimento de que a subjetividade do indivíduo é também uma mercadoria a ser consumida pelos demais indivíduos no âmbito de uma interação social, bem como uma mercadoria a ser consumida por meio da compra efetuada pelas campanhas publicitárias que moldam a possibilidade de que o indivíduo possa trilhar os rumos de sua individualização. Neste último caso, o sucesso da estratégia de marketing das campanhas publicitárias se dá quando conseguem abocanhar o consumidor.

Por isso, Colin Campbell entendera que a afirmação da individualidade não está no produto adquirido em si, mas nas reações para com os produtos e, com isso, a descoberta de si desempenhada pelo sujeito no âmbito de sua personalização está no ato de consumir com a finalidade de se autoconhecer (CAMPBELL, 2006, p. 52-53). Consequentemente, desponta-se uma esfera de individualização gerada mediante a subjetividade desempenhada pelas campanhas de venda de mercadorias que fazem do indivíduo um 
bem a ser consumido de acordo com determinados critérios, isto é, o indivíduo também é consumido a partir do momento em que se possibilita definir sua individualidade mediante uma relação de consumo.

Parece ser justamente em decorrência disso que Anderson Moebus Retondar concluiu pela existência de um sistema padronizador dos indivíduos enquanto consumidores (RETONDAR, 2007, p. 70). A colocação à venda do próprio consumidor ao se submeter às relações de consumismo se ampara em uma padronização de seu status, fazendo com que a sociedade de indivíduos seja reconhecida como uma sociedade que atende a um padrão de conduta consumista. Porém, não se pode olvidar que, apesar de o indivíduo atender a um padrão de agir, ele só pode fazer isso devido à sua liberdade fornecida pelo contexto pós-moderno, o que viabiliza a possibilidade de que venha a buscar se personalizar.

Nessa esteira, como concebera Zygmunt Bauman, o consumismo aparece como um arranjo social advindo da reciclagem de vontades, desejos e anseios humanos com a finalidade de se transformar na força que propulsiona e operativa a sociedade, momento onde é desempenhado um importante papel de autoidentificação individual e de grupo (BAUMAN, 2008, p. 41). Por certo que neste ponto o problema que decorre da individualização é justamente a forma como esta vem a ser incorporada pelas relações de consumo, as quais no uso de suas estratégias publicitárias vendem uma afirmação individual.

Para tanto, o indivíduo ao consumir também está sendo consumido, pois busca sua personalização em um contexto incorporado pela subjetividade a partir de campanhas publicitárias, desenhando o contorno pós-moderno em que a propiciação da individualização acaba por definir a armadilha na qual o sujeito que busca pela sua personalização termina sendo padronizado pelo segmento que consome.

Diante da situação apresentada, o consumismo gerado na democracia pós-moderna que viabiliza a individualização e a autonomia em um relaxamento da verticalização estatal tende a ser predatório para com os recursos naturais e a natureza como um todo. Para um cenário de massificação do consumismo, a nefasta apropriação da natureza em processos de produção se faz sem restrições. Enquanto livremente o indivíduo se personaliza, livremente o ambiente é destruído.

Em decorrência disso, tem-se por fundamental que se contextualize a crise ambiental pós-moderna também como um advir consequente das relações de consumo. Eis que na pós-modernidade a produção deixa de ser o desafio, dando lugar ao 


\section{LEAL, A. A. F.}

consumismo e, justamente por não ser mais um desafio, a produção é massificada para atender a demanda dos consumidores, sendo inevitável que dessa demanda se chegue à questão da crise ambiental, diante do esgotamento dos recursos naturais e da degradação compulsiva da natureza.

\section{Das relações de consumo à crise ambiental}

Se o sistema econômico atual encontra um limite ecológico, como entendera Plauto Faraco de Azevedo, então, realmente é preciso alterar a rota (AZEVEDO, 2008, p. 150). O problema estaria, porém, justamente em guinar para uma nova perspectiva, tratando-se de uma sociedade pós-moderna que se volta para o consumismo como um meio de individualização.

Não se pode, contudo, aceitar a possibilidade de reverter a flexibilização que ocorreu na relação entre Estado e indivíduo, pelo elo da sociedade democrática pósmoderna com a finalidade de reestruturar uma perspectiva de controle. Está-se em um estágio de evolução social que não necessita ser inviabilizado, mas readequado às suas novas perspectivas, propiciando um novo paradigma.

De acordo com Francis Fukuyama, uma sociedade que possui sucesso em um momento histórico, não necessariamente será sempre bem-sucedida, devido à decadência política e, com isso, ainda que a democracia liberal seja hoje a forma mais legítima de governo, sua legitimidade pode existir somente em decorrência de seu desempenho (FUKUYAMA, 2013, p. 522). Esta perspectiva não pode ensejar a recusa de um sistema democrático estabelecido socialmente na atualidade, sob a justificativa de possibilitar a preservação da natureza. Contudo, é necessário considerar a crise ambiental originada pela atuação das relações de consumo em um ambiente no qual se opera a escassez dos recursos naturais e a degradação ambiental, para que se possa dispor sobre meios de preservar a natureza.

Neste ínterim, a crise vivenciada nas relações que interferem no meio natural estão predispostas em uma relação entre homem e natureza. Como entende François Ost, no âmbito de uma agrura da relação do homem com a natureza, existe uma crise do vínculo e uma crise do limite. A crise do vínculo corresponde à dificuldade de discernimento da ligação do homem para com a natureza e a crise do limite, por sua vez, evidencia a dificuldade de distinção entre o que o homem difere da natureza (OST, 1997, p. 9). 
Essa crise paradigmática que se desenrola nas relações entre sociedade e natureza faz com que o homem passe a se apropriar da natureza, buscando transformar este universo a seu favor (OST, 1997, p. 53). É por isso que as relações de consumo são observadas em um cenário no qual os processos sociais interferem, a título da intervenção do capital e dos Estados, nas modalidades de transformação do ambiente (LEFF, 2010, p. 54). Tem-se, com isso, uma atividade desregrada de consumo que é viabilizada por intermédio de uma relação de dominação exercida pelo homem sobre a natureza. O nível massificado de produção de mercadorias já não é mais um problema tecnológico, sendo a verdadeiro obstáculo fazer com que o consumo continue aumentando imoderadamente.

É justamente essa herança da modernidade que no ambiente pós-moderno evidencia a crise ambiental vivenciada. A autoproclamação de rei realizada pelo homem gerou a coisificação da natureza, que passou a ser vista somente como um estoque de recursos naturais. Com efeito, a sociedade de consumo, a fim de que cada vez mais possa consumir, necessita produzir a nível de garantia deste objetivo. Isso se faz de tal modo que a natureza passa a ser vista apenas como um depósito de resíduos ao bel-prazer do homem, como bem observara François Ost:

\begin{abstract}
A modernidade ocidental transformou a natureza em ambiente: simples cenário no centro do qual reina o homem, que se autoproclama dono e senhor. Este ambiente cedo perderá toda a consistência ontológica, sendo desde logo reduzido a um simples reservatório de recursos, antes de se tornar um depósito de resíduos - em suma, o pátio das traseiras da nossa tecnosfera. (OST, 1997, p. 10)
\end{abstract}

Não é somente pelo fato de o consumidor estar constantemente volitando de desejo em desejo na busca pela sua individualização que o torna um consumidor contumaz, pois também há a personalização intentada por intermédio das relações de consumo que se relaciona com um imperativo de "descartar e substituir" (BAUMAN, 2008, p. 50). A imperatividade que o consumo opera na subjetividade dos indivíduos que tencionam se originalizar leva sem dúvidas à um desperdício constante de mercadorias. Ponto em que não se pode olvidar o fato de que estas mercadorias necessitam em demasia de recursos naturais para serem fabricadas, sendo que, ao final, no seu descarte se torna necessária uma irônica e "florescente indústria de remoção do lixo" (BAUMAN, 2008, p. 31). De fato, a priorização do lucro constante das relações de consumo leva inevitavelmente à deterioração do ambiente sendo que, por vezes, a questão econômica desconsidera que a riqueza é baseada em energia e recursos naturais, continuando a exigir cada vez mais capital para sua extração em locais cada vez mais degradados e inacessíveis (CAPRA, 2006, p. 219). 


\section{LEAL, A. A. F.}

A constante ampliação do consumo por intermédio de mecanismos publicitários e estratégias de marketing em um ambiente político propício leva consequentemente a uma agir predatório em face da natureza. Valendo-se da finitude dos recursos naturais e da energia necessária para a produção dos bens, as relações de consumo da sociedade atual não condizem com a preservação do ambiente. Se o consumo é ampliado em uma escala cada vez mais constante em um ambiente de fluidez de informações, no qual os "globais dão o tom e fazem as regras do jogo da vida" (BAUMAN, 1999, p. 8), por certo que a produção é elevada cada vez mais ao seu grau máximo, agindo sobre a natureza de uma maneira irresponsável e desregrada.

O ambiente passa a ser totalmente desconsiderado, sendo o mais importante produzir para massificar o consumismo. A natureza somente é considerada quando importa em um efetivo problema de produção para as relações de consumo que são um dos sustentáculos das relações sociais pós-modernas. Por certo que o indivíduo somente é um mero consumidor, induzido a consumir sem analisar as consequências que seu consumo desregrado implica na questão ambiental. Neste sentido, conforme Agostinho Oli Koppe Pereira, Henrique Mioranza Koppe Pereira e Mariana Mioranza Koppe Pereira:

\footnotetext{
O ser humano, transformado em consumidor, é induzido a não pensar sobre o porquê do comprar e consumir. Pela mesma racionalidade, esse mesmo consumidor não pensa nas consequências que esse consumo pode trazer ao meio ambiente. (PEREIRA; PEREIRA; PEREIRA, 2009, p. 18)
}

O consumismo, compulsivo e imediato por natureza, representa a irracionalidade humana nas relações de consumo. O homem, no âmbito de seus desejos, busca se personalizar e moldar sua originalidade diante de sua autonomia e, paradoxalmente, acaba sendo padronizado neste agir coletivo de consumo pelo mero consumo. Ao se individualizar, passa a ser coletivizado por uma subjetividade advinda de campanhas publicitárias e estratégias de marketing que apostam nas marcas e na sua imagem para criarem no indivíduo a ideia de que ele pode moldar sua identidade, tudo isso em um espaço onde "as ordens são locais, ao passo que a elite e as leis do livre mercado a que obedece são translocais" (BAUMAN, 1999, p. 133).

A globalização gerada pela massificação do consumismo, operada em um constante fluxo de informações como é demonstrado pela pós-modernidade, implica em uma reordenação da operação de livre mercado na qual o lucro como consequência das relações de consumismo é angariado independentemente da responsabilidade. Com efeito, depreende-se uma irresponsabilidade conjunta entre o indivíduo e a produção de 
mercadorias para consumo no que tange à degradação ambiental. A finitude de recursos não é considerada no auge dos riscos e perigos provenientes da esfera econômica, mormente quando da causa do consumismo. Conforme estudo realizado sobre a sociedade de risco, Cristiano Luiz Lenzi entende que

\begin{abstract}
Ao se deixar instrumentalizar pela esfera econômica, buscando uma produtividade crescente a qualquer custo, a ciência desenvolve uma cegueira sistemática diante dos riscos e perigos ambientais. (...). Interesses políticos e econômicos podem moldar e influenciar a forma pela qual percebemos os riscos. Esses interesses perpassam as relações de causa e efeito que são construídas entre ações humanas e o impacto ambiental. (LENZI, 2006, p. 138139)
\end{abstract}

De certo que o crescimento econômico e a necessidade de produtividade crescente tornam despercebida muitas vezes a degradação ambiental e os riscos gerados. Porém, é também em razão do consumismo e sua demanda pela produção que se tem o quadro da crise ambiental da pós-modernidade. Como atesta Cleide Calgaro, enquanto o consumo for mal utilizado, inevitavelmente produzirá a problemática da exploração e da dependência (CALGARO, 2009, p. 66). Para tanto, não é a toa que se evidencia a elevação ao máximo da produção de bens em decorrência da demanda inconsequente de uma sociedade de consumo, na qual as relações sociais se baseiam na mercantilização dos indivíduos, padronizados que são na sua busca pela individualidade. Por via de consequência, as relações de consumo inevitavelmente acabam sendo uma das principais causas que desembocam na crise ambiental vivenciada.

\title{
Conclusão
}

Como referido, a sociedade pós-moderna apresenta um novo estágio da relação entre indivíduo e Estado, mais flexibilizado e menos verticalizado. Neste cenário social, as relações de consumo se apresentam cada vez mais fluídas e diversas, nas quais o indivíduo busca se individualizar por meio da personalização que o consumo alega permitir.

Conforme analisado nesta pesquisa, a sociedade em seu estágio mais avançado, vislumbrada pela ótica do que se refere como pós-modernidade, está baseada em uma democracia que atesta um novo ideal na relação entre indivíduo e Estado. A verticalização passa a sair de cena, dando azo ao indivíduo que vê poucos limites para estabelecer sua individualidade.

O processo de individualização dos membros desta sociedade pós-moderna, inseridos em um contexto cultural que são, evidencia a busca pela autonomia dos 


\section{LEAL, A. A. F.}

indivíduos em um espaço democrática permissivo. Consequentemente, a possibilidade que se tem para a individualização leva o indivíduo a buscar esta autonomia por meio da originalidade oferecida pelos bens de consumo e, justamente por isso, as relações de consumo lançam mão de estratégias de marketing e campanhas publicitárias que objetivam adentrar à subjetividade vendendo individualidades.

Paradoxalmente, ao buscarem sua personalização, constatou-se que os indivíduos acabam sendo padronizados em uma sociedade de consumo, onde o ter passa a ser o ser. Muito embora o indivíduo possa escolher pela sua mercadoria, é ele quem passa a ser escolhido, mercantilizado e vendido em um processo de relações de consumo baseadas na publicidade e em estratégias focadas pela venda de produtos produzidos em massa.

Este cenário truculento da pós-modernidade no qual as relações de consumo são a liberdade e a prisão dos membros da sociedade democrática resulta em uma situação atroz para o ambiente. A produção em massa, o consumismo desregrado e o descarte instantâneo desconsideram a finitude dos recursos naturais bem como a degradação ambiental. Ponto no qual a natureza deixa de ser vista como parte de uma relação social para tomar a forma de um mero estoque de recursos.

Com efeito, conclui-se que o processo de individualização dos membros de uma sociedade por meio do consumo, está intimamente relacionado com as principais causas que consolidam a crise ambiental.

Referida constatação leva à extrema e essencial importância de uma reconsideração do consumismo da pós-modernidade, por ferramentas que viabilizem a preservação do ambiente, demonstrando a importância que este segmento possui para a contenção de um iminente colapso ambiental.

\section{Referências}

ARISTÓTELES. A política. Tradução de Nestor Silveira Chaves. Rio de Janeiro: Nova Fronteira, 2011.

AZEVEDO, Plauto Faraco de. Ecocivilização: ambiente e direito no limiar da vida. 2 ed. São Paulo: Editora Revista dos Tribunais, 2008.

BAUMAN, Zygmunt. Em busca da política. Tradução de Marcus Penchel. Rio de Janeiro: Zahar, 2000.

BOBBIO, Norberto. Teoria geral da política: a filosofia política e as lições dos clássicos. Tradução de Daniela Beccaccia Versiani. Rio de Janeiro: Elsevier, 2000 
CALGARO, Cleide. Desenvolvimento sustentável e consumo: a busca do equilíbrio entre o homem e o meio ambiente. In: PEREIRA, Agostinho Oli Koppe; HORN, Luiz Fernando Del Rio. Relações de consumo: meio ambiente. Caxias do Sul: Educs, 2009.

CAMPBELL, Colin. Eu compro, logo sei que existo: as bases metafísicas do consumo moderno. Tradução de Niza Neves Cheroto. In: BARBOSA, Lívia; CAMPBELL, Colin. Cultura, consumo e identidade. Rio de Janeiro: Editora FGV, 2006.

CAPRA, Fritjof. O ponto de mutação. Tradução de Álvaro Cabral. São Paulo: Cultrix, 2006.

CARNOY, Martin. Estado e teoria política. Campinas: Papirus, 1988.

DIAS, Reinaldo. Ciência política. São Paulo: Atlas, 2008.

ELIAS, Norbert. A sociedade dos indivíduos. Organizado por Michael Schröter. Tradução de Vera Ribeiro. Rio de Janeiro: Jorge Zahar Ed, 1994.

FREITAS, Juarez. Sustentabilidade: direito ao futuro. Belo Horizonte: Fórum, 2011.

FUKUYAMA, Francis. As origens da ordem política: dos tempos pré-humanos até a Revolução Francesa. Tradução de Nivaldo Montigelli Jr. Rio de Janeiro: Rocco, 2013.

GIDDENS, Anthony. As consequências da modernidade. Tradução de Raul Fiker. São Paulo: Editora UNESP, 1991.

Globalização: as consequências humanas. Tradução de Marcus Penchel. Rio de Janeiro: Jorge Zahar Ed., 1999.

LEFF, Enrique. Epistemologia ambiental. Tradução de Sandra Valenzuela. São Paulo: Cortez, 2010.

LENZI, Cristiano Luis. Sociologia ambiental: risco e sustentabilidade na modernidade. Bauru: Edusc, 2006.

LIPOVETSKY, Gilles. A era do vazio: ensaios sobre o individualismo contemporâneo. Tradução de Therezinha Monteiro Deutsch. Barueri: Manole, 2005.

OST, François. A natureza à margem da lei. Tradução de Joana Chaves. Lisboa: Instituto Piaget, 1997.

PEREIRA, Agostinho Oli Koppe; PEREIRA, Henrique Mioranza Koppe; PEREIRA, Mariana Mioranza Koppe. Hiperconsumo e a ética ambiental. In: PEREIRA, Agostinho Oli Koppe; HORN, Luiz Fernando Del Rio. Relações de consumo: meio ambiente. Caxias do Sul: Educs, 2009.

PEREIRA; Agostinho Oli Koppe; CALGARO, Cleide. A modernidade e o hiperconsumo: políticas públicas para um consumo ambientalmente sustentável. In: PEREIRA; Agostinho Oli Koppe; HORN, Luiz Fernando Del Rio. Relações de consumo: políticas públicas. Caxias do Sul: Plenum, 2015. 
RETONDAR, Anderson Mobeus. Sociedade de consumo, modernidade e globalização. São Paulo; Annablume; Campina Grande: EDUFCG, 2007.

SANTOS, Boaventura de Sousa. Para um novo senso comum: a ciência, o direito e a política na transição paradigmática. V. 1. A crítica da razão indolente: contra o desperdício da experiência. 8 ed. São Paulo: Cortez, 2011.

TAVARES, Fred; IRVING, Marta de Azevedo. Natureza S/A? O consumo verde na lógica do Ecopoder. São Carlos: RiMa Editora, 2009.

Recebido em 21 ago. 2018 / Aprovado em 30 maio 2019

Para referenciar este texto:

LEAL, Augusto Antônio Fontanive. Personalização, consumo e transtornos ambientais. Prisma Jurídico, São Paulo, v. 18, n. 2, p. 189-207, jul./dez. 2019.

https://doi.org/10.5585/PrismaJ.v18n2.10319. 